DOI: 10.1515/pcssr -2017-0006

\title{
Aleatorism and Sporting Performance
}
Authors'contribution:
A) conception and design of the study
B) acquisition of data
C) analysis and interpretation of data
D) manuscript preparation
E) obtaining funding

\author{
Jerzy Kosiewicz \\ Josef Pilsudski University of Physical Education in Warsaw, Poland
}

ABSTRACT

A sporting spectacle is an important cultural event, essentially influencing social and individual lives. In spite of this, there does not yet exist a monograph that analyzes, describes, and explains sporting performance from the point of view of aleatorism as part of the theory of sport and physical culture. Unfortunately, no monograph has developed this issue in a multi-aspectual, holistic, culturological, and philosophical way, dealing with its axiological values (aesthetic and praxeological). This applies to the relations between this phenomenon and the mechanisms that bring about the development and growth of interest in the social dimension.

Generally, the theory of aleatorism has been applied in analyzing the phenomena of physics, music, and theatrical spectacle. The one relatively well-developed theory of performance is that of theatre spectacle.

The above does not mean that the author aims to appreciate a sporting performance due to its links with theatre. He points to one of many possible aspects of a sporting spectacle, which are the assumptions of an aleatory nature included in its structure, plan, and the tactics of the game.

KEYWORDS Aletorism, professional sport, spectator sport, theatrical spectacle, sporting perfomance

\section{An attempt at defining a sporting performance ${ }^{1}$}

The sporting spectacle is etymologically related primarily to theatre (Latin spectare = to watch, spectaculum $=$ show, spectacle). The terms "show" and "spectacle" are used to describe theatre performances. These terms pertain equally well to dramatic theatre, puppet theatre, ballet, pantomime, and circus. It is also appropriate to speak of the concept of spectacle in relation to such areas as religion, politics, and sport. It is said that the spectacle is a phenomenon of global life that an individual uses to impress others with his or her abilities (Raszewski, 1991, p. 35). It involves the suspension of everyday routine, creating the impression of an unusual and unique deep emotional bond between the mutually influencing competitors and spectators.

Without going into specific definitions of the specific traits or various forms of the theatrical and sacred in political spectacles, and without going into their common and unique traits, we can state that the sporting spectacle is understood to mean an audiovisual (primarily visual) sporting event that is ludic, primarily devoted to entertainment through the presentation of athletic competition, the competitors' abilities and dexterity according to determined rules and regulations, and with the participation of athletes, judges, and spectators who mutually influence each other for the duration of the spectacle. 


\section{The game plan or script}

Discussing concepts associated with theatre scripts, historian and theatre expert Zbigniew Raszewski noted that they are connected with the concept of "playing," and that from the point of view of a spectacle or play, they are also connected with musical, theatre, and sports presentations (Raszewski, 1976, pp. 105-147). Music requires instruments and musicians, theatre requires actors, and sports, originally and currently treated as a form of playing (e.g., so-called "sports for everyone," or recreational sports), require at least two partners who obey a set of accepted rules. Although it may be hard to notice the similarity between a sporting event - for example, a soccer game - and a performance of Hamlet or a symphony concert, all three activities fall under the concept of games (entertainment). The meaning of that concept, explained above, is very old and comes from the Latin "ludus."

Z. Raszewski stated that in the past (for instance, in the Middle Ages) the term "game" was more frequently and usually used to refer to theatre than it is today. A play was called "game" (e.g., ludus paschalis). Evidence of this has remained in the names used by many languages to denote an actor (Schauspieler, herec, grajek, player). This suggests that in the past more similarities were seen between the areas of group entertainment, athletic competition, theatre, and music than are today. It is characteristic that these three forms of play have been classified together as spectacles and art. It is impossible to "play" in any other form of art; one cannot "play" in painting, architecture, or poetry. Also, no game is as visually stimulating as a theatre or sporting spectacle.

The three types of games mentioned (concerts, theatre plays, and sporting events) have at least one common characteristic: they are based on a predetermined idea, a presentation design included in an instruction. In all three, somebody has to foresee and set a certain behavior pattern, or in other words, foresee and script the actions of the partners in such a way as to avoid having their respective ambitions lead to anarchy and chaos (Raszewski, 1976, p. 105). Naturally, these instructions are different in all three cases. In the first two forms, the scripts deal with art; they are artistic. In most cases, the authors of both the musical score and theatre script, despite the obvious differences in their form, accept a faithful presentation of their message and a consistent exercising of their theatrical or musical ideas. Raszewski wrote that

"the author expects full obedience from his partners because he foresees the outcome of the game precisely. He doesn't want to, he can't, hedoesn't know how to make a statement except through performers. He will use all his ingenuity to impress his concept on them" (Raszewski, 1976, pp. 105-106).

Raszewski took a different view of scripts for sporting games, mostly because of the final aim. Sports "are at their best when they free the players' ingenuity, letting them play the game according to their preference, as long as it is in accordance with the rules" (Raszewski, 1976, p. 105).

Considering the traditional view, which does not include the concept of the modem aleatory forms of music and theatre, one could indeed reach the conclusion that in the formal sense a sports game, which is characterized by coincidence and freedom of action, is so different from the rigid musical or theatre works, full of unquestioning respect for the author's intended message, that it would be pointless to compare it with a theatrical or musical performance that is supposedly lacking in any coincidental or random actions or activities.

However, all three forms of games and the projects upon which they are based - their scripts - can be interpreted in a completely different way, taking into consideration the concept of aleatorism. This concept also sheds a different light on the ingenuity of competitors who play a sports game according to their own discretion. One can see then that in sporting events it is also impossible to have the competitors play the game according to their "whims." They may only play according to a predetermined script that includes constant tactical and technical goals based on the theory of training and sports competition and that, as is the case with music and aleatory theatre, takes into account the necessity of coincidence as an enriching element that enhances a game, an artistic statement, or a theatre or sports performance.

In addition to this, when described in an aleatory way, all three forms have types of scripts that are similar in their general assumptions, i.e., they contain specific constant elements as well as possible but 
optional accidental ones that may complement the structure of predetermined constant elements.

\section{The sports game and spectacle as aleatory phenomena}

Aleatorism is a musical trend that appeared only in the twentieth century. It introduced coincidence as a theoretical and aesthetic concept (although it had been known and used as an element in music for a long time), as well as an element lending additional attractiveness to both old-fashioned composition and to the performance.

Just as in totally scripted music and theatre, nothing could be completely precise. Therefore, in aleatory music, which held coincidence as the most significant element, not everything could be fully coincidental or unpredictable, if for no other reason than because in art, music, or sport, true unpredictability is extremely rare. It is true that unpredictability does play a part in their scripted structures and presentations, but it cannot dominate, otherwise there would be no composition, no script writing, no formation of a sports strategy, i.e., the script of a sports event. The coincidence is bound by certain frames or borders. This is done by the composer and conductor, as much as by the director and playwright or coach and manager. These borders frame the entire duration, leaving the details to coincidence.

Aleatorism, whether in music, theatre productions (e.g., commedia dell'arte or instrumental theatre; Schaffer, 1983, pp. 473-474), or in sports, is not a true improvisation, as the whole concept is outlined beforehand and the outline contains constant unchangeable elements of the game, between which the enriching unpredictable elements are allowed.

It is certain that in all three cases - aleatory music and theatre, as well as in a sports event - the author, i.e., the composer, conductor, playwright, director, coach, or manager, is trying to achieve unpredictability. In music, as B. Schaffer noted, the composer is mostly trying to surprise him or herself as the first and most important listener because the composer and the few other people who know the score are the only ones who know what the constant elements are and which parts are coincidental events that enrich the scripted core.

There is a similar relationship between the playwright (and director) and the spectacle, but here the unpredictability exists both in the relationship between the director and the actors (to whom the director more or less gives freedom to engage in unpredictable activity) and between the actors and the audience (which may be provoked by unexpected actions of the actors, as is the case with Meyerhold's theatre), as well as, albeit to a lesser extent, in the relationship between the actors during the performance.

The surprise that is valued in sports is the surprise at oneself, i.e., the manager and competitor who plan the general outline of the game and are then surprised by the unpredictable success of the original plan. There is also a high value placed on surprising the players of one's own team (a player surprises his or her teammates with certain "characteristic" behaviors). Even more highly thought of is surprising the spectators, since they are the ones who provide the team's income. The highest value, however, is awarded to surprising the opposing team and its coach. Such surprise shows disorder in the opponents' ranks and facilitates victory. Thus, the relations caused by and concerned with unpredictability can be much more highly evolved and complicated in sports than in music or aleatory theatre due to the more complicated nature of the social structures involved in sporting spectacles.

Aleatorism leaves room for individual interpretation (not to be confused with improvisation) and individual creative inspiration in music and theatre just as much as in sporting events. It rejects the passive, thoughtless recreation of predetermined assumptions; it stimulates actions that are not automatic, so that they are thought out and at the same time spontaneous, intentionally discrete, and, most importantly, unique and interesting through their unconventionality (though aleatorism is a convention) and original solutions.

As a result, we have a musical performance, a theatre show, or a sporting event that always provides different sensory experiences, sometimes far removed from any prior concepts of the composer, conductor and listeners, playwright, director and audience, manager, or coach and fans.

Because certain general frames allow for coincidence, it is impossible to fully predict the final, very broad results of all musical, theatrical, or athletic actions, whether positive or negative, although it is the former type with which aleatoristic concepts are concerned. 
This brings us to the question of whether aleatory scripts - for musical, theatre, or sporting spectacles - have an inherent conscious abandoning or limiting of the author's ingenuity or inspiration. Is it not proof and testimonial evidence of the author's powerlessness and creative weakness when there is a percentage of chance in their creations, leaving part of their duties to an unknown quantity? Well, it turns out that this is not the case, as creating such a script for a musical performance, stage work, or sporting spectacle (a script based on such things as sports competition theory, frequently on long-term preparations and extensive information) is a very complicated and time-consuming process. Frequently, the outline of the script is transformed during writing into a final version that is very different from the original idea - the original vision of the composer, playwright, or manager. The more attention they pay to details, the less time they can devote to the musical composition, theatrical show, or sporting spectacle as a whole.

An aleatory interpretation of a "score" for a sporting spectacle, the game plan and concepts of a sports competition, as well as, for a musical composition, a play or a script, offers a higher chance of concentrating on the most important factors, which are generally outlined and not filled in with details. And thus aleatory concepts allow one to determine the most important components, as well as those that fill in the predetermined construction that these components make up. In this sense, aleatorism does not leave everything to chance. It is in fact cautious in this area, since our knowledge of coincidence is far from complete. A chain of coincidences is neither changeable nor constant: It is indeterminate.

"We can't expect it to have any properties and despite that we are able to determine a certain,

naturally transcendental rule. The more elements making up a coincidental series, the greater

its equilibrium" (Schaffer, 1975, p. 21).

Thus, if the substance of the theatrical or sporting spectacle or musical score leaves enough free space, then the observed sample of interpretations will take on certain statistical properties. This means that, statistically speaking (on average), regardless of the arrangement of the material being observed and researched, each element will - and this is very significant - be represented equally strongly and frequently (Schaffer, 1975, p. 21). This is particularly visible on statistical printouts (made either during or after the competition) concerned with sporting events, e.g., in soccer, tennis, and boxing.

Because of these statistical properties, we can to some degree predict certain outcomes, i.e., we can determine the number of chance elements (approximately and based on statistics).

In addition, aleatorism enables unintended and unpredictable elements to be included in a theatrical, sporting, or music performance. It accepts the fact that these factors will play a certain, sometimes significant, role in the final shape of the spectacle, e.g., a philharmonic concert, and that they will have a certain influence on carrying out the original game plan. From this point of view, leaving certain things undetermined can be just as creative as determining all of the elements.

\section{Final reflections}

From the point of view of basic formal assumptions, a sporting spectacle contains aleatory characteristics similar to those of certain musical compositions or theatrical shows. However, the differences, both in the areas of constant, predictable elements and random ones, are too obvious and so basic that they are not even comparable. This is true of their structure and function as well as of teleological concepts, i.e., purpose, meaning the message conveyed by their content and merits.

A sporting spectacle (viewed primarily from the angle of competition) containsconstant elements of the game plan appropriate to the spectacle itself and the discipline it involves, i.e., primarily tactical assumptions carried out on the basis of the appropriate technical, conditioning, and physical training of the competitors. Both the constant and coincidental elements, as well as the constant and coincidental technical solutions, are mostly intended for achieving practical or pragmatic praxeological ends, mainly achieving victory or beating a record. All properties of the spectacle are instrumentally and axiologically subordinated to this end. This is true of all aesthetical and ethical aspects, as well as educational, health, and cognitive elements.

It is for this reason that the sporting spectacle differs fundamentally from a game or artistic 
performance and aleatory art forms. In these art forms, the game plan and various aleatory structural elements are subordinated primarily to artistic concepts, conveying an aesthetical message in order to stimulate the strongest aesthetic experience (with a stress on art). All other properties of art, including the educational, practical, religious, and moral characteristics, are instrumentally and axiologically subordinated to artistic concepts, which are an end in themselves, i.e., an end that is strictly autotelic in character.

It should be added that the internal structure of a musical spectacle or theatrical show does not contain the concept of competition or victory of certain elements included in the score or game plan. These constant and coincidental elements are composed in such a way that they lead to the creation of a work of art - to the artistic success of a composer, conductor, musician, director, or actor - not though mutual competition, but through cooperation.

${ }^{1}$ In the main text, in relation to the properties of a sports spectacle, the notion of sport is discussed in an abbreviated way in order to adjust it to the central thought - the content of the argument. In the literature on the subject, there are many more interpretations related to this notion. For example, I can quote a description characteristic for sport social sciences presented by D. Malcolm (2008, pp. 238-239), referring to A. Guttmann (2004), B.D. McPherson (1989; see inter apian. Elias \& E. Dunning1986; J. Coakley \& E. Dunning, 2000), and E. Dunning (2002). He proclaims that it is common practice for the term "sport" to be used interchangeably with the terms "play" and "game," whereas he is of the opinion that these are different notions, despite the fact that attempts to define sport usually refer its qualities to the abovementioned terms. Referring to Guttmann, Malcolm writes that the most general of the non-utilitarian forms of activity of a physical and mental character is the category of play. It has strictly autotelic - not instrumental - qualities. It refers neither to health-oriented aims, nor to personal development, nor to physical or mental fitness, nor to earning a living. Thus, for example, school and extra-curricular physical education or professional sport are not forms of play. As Malcolm proclaims after Guttmann, play can come into existence in a spontaneous or organized way. If play has an organized character, we are dealing with a game. A game can be based on competition (competitive game) or take place without it (non-competitive game). The term refers to various activities: competitions (like popular polevault competitions), fights, contests, strictly physical rivalries (a sin contact and non-contact sports), and intellectual rivalries (I would like to add that it can also have a mixed character).

However, Malcolm, who presents Guttmann's views, is of the opinion that, in spite of the fact that there is indubitably an intellectual component to sport, its character is determined by physical effort, which is immanently integrated into its structure (except for chess and bridge as a sport), and which is based on specific physical fitness and developed skills. However, in contrast to real fights or wars, the abovementioned rivalryis based on a playful game. It takes place in a joyful way. It also has qualities that are characteristic for play: autotelic values. Guttmann creates a very general and, simultaneously, one-sided definition of sport that passes over traits of highly qualified, highly competitive, professional, Olympic, or spectacular sport. He proclaims that sport can be defined as an activity including a competition, fight, or contest of organized character, or a rivalry including elements of joyful game and play of a nonutilitarian character, where physical competences (conditions) take precedence over intellectual ones ("sports can be defined as organized contests of a playful, non-utilitarian character in which the physical demands outweigh the intellectual components" - Malcolm, 2008, p. 238). That definition comes from the first edition of Guttmann's book, published in 1978. It is probably the reason that sport was saturated with autotelic qualities characteristic of earlier times for Coubertin and his followers. They negated professional sport treated in a utilitarian, instrumental way, that is, as a means for other non-sport aims. Malcolm also presents McPherson and his co-authors' interpretation of sport (McPherson, Curtis \& Loy, 1989). They distinguish its four most important qualities. A significant criterion enables the evaluation of how advanced a given sport is and its level of competences and structuration. A proper structure (formal assumptions) is significant for sport even in its informal forms. It is necessary, for example, for children's street or backyard football, or for playing baseball in the park. In those and in other cases, the course of the game is determined by rules that are known and accepted by its participants. This type of sport has a low level of formal structure. A higher level of structuration is characteristic, for example, of the Football World Cup. Its preparation and course are strictly controlled by great bureaucratic sport and non-sporting institutions, which are established, among other things, to do that on the basis of previously accepted rigorous rules.

The second significant quality of sport is the fact that it is goal oriented on variously understood success. It depends on criteria that, as in the criteria for failure, are usually clearly defined.

The third characteristic feature of sport is rivalry between particular athletes or teams, whereas the fourth quality 
is, in their opinion, its ludic character. They maintain that sport is ludic, which implies, according to them, that sport also includes qualities characteristic for play and game. They justify this in an etymological way, as the term "ludic" comes from the Latin "ludus," which means "play" or "game." In summary, it can be proclaimed that sport, according to McPherson and his co-authors, is a structured, competitive form of game, which is teleologically oriented toward success.

In the abovementioned definitions, it is possible to notice the implicitly rooted cultural messages. This is confirmed by N. Elias and E. Dunning (1986), who point out that contemporary sport refers to patterns of competitive physical activities, which appeared in Britain and Ireland in the seventeenth and eighteenth centuries. It is also possible to point to different understandings of similarities and differences between play, game, and sport. For example, G. Tomc (2008) discusses these notions, referring to B. Suits (1995a; 1995b; see and compare: 2016) and. K.V. Meier's viewpoint (1995) and, in opposition to them, presenting his own understanding of these terms. He proclaims that "For Bernard Suits, sport may or may not be play [if it is involuntary or extrinsically motivated, it is in his opinion not play] may or may not be game [he distinguishes sport games in which rules are the crux of the matter, like soccer, from sport performances, in which ideals are essential and to be approximated, like gymnastics]." For Klaus V. Meier, sports may or may not be (as in Suits), but are necessarily, games (they require physical skill by the participants in pursuing the goal of the game), although not all games are sports - for example, chess or poker (Tomc, 2008, p. 9).

Then, G. Tomc, considering the qualities of play, game, and sport and the relations between them, and also taking into account performances, rituals, and experimentation, comes to the conclusion that there are:

- "games [in which the parallel world of pretense is created by players trying to approximate an ideal skill, for example a physical skill in sport],

- performances [in which a parallel word of pretense is created by players trying to approximate an ideal representation of life, for example an aesthetical production],

- rituals [in which a parallel world of pretense is created by players trying to approximate ideal behavior, for example an aesthetical production] and

- experimentation [in which a parallel world of pretense is created by players trying to approximate an ideal classification of the world, for example in scientific research].

It follows from our theoretical perspective that

- all sports are either games or performances,

- all games and performances are not sport,

- but all games and performances are forms of playing" (Tomc, 2008, p. 9).

I present these two quotations and not their discussion because Tomc presents the viewpoints of Suits and Meier, as well as his own, in a highly essential way. Hence their synthetic interpretation could deform their content. What is significant in this case are also original expressions. By the way, such a type of formal solution is permissible also in notes or stage directions constituting marginal currents of considerations in their relation towards the central statement.

Tomc's considerations correspond to S.R. Kretchmar's views (2008) and even to the main ideas of the paper presented one year later by Kretchmar during the Conference of the International Association for the Philosophy of Sport in Seattle in August 2009, entitled "Do Games Require Artificial Problems That are Neither Too Hard Nor Too Easy?". It is possible to notice that reservations about Suits' conception presented by the outstanding Slovenian sociologist can be referred to some degree to the paper of the American philosopher of sport (Kosiewicz, 2010b, p. 5$32)$.

The other aspects and properties of sport have been presented by the author in the following books and papers (inter alia): Kosiewicz, 2010a; Kosiewicz, 2010b, pp. 5-32; Kosiewicz, 2012, pp. 65-101; Kosiewicz, 2014a, pp. 5-22; Kosiewicz, 2014b, pp. 23-31; Kosiewicz, 2014c, pp. 32-47; Kosiewicz, 2014d, pp. 48-63; Kosiewicz, 2014e, pp. 64-73; Kosiewicz, 2014f, pp. 60-78; Kosiewicz, 2015a, pp.; Kosiewicz, 2015b, pp.; Kosiewicz, 2016a, pp. 79-87; Kosiewicz, 2016b.

\section{REFERENCES}

Coakley, J. \& Dunning, E. (2000). Handbook of Sport Studies. London: Sage.

Dunning, E. (2002). Figurational contributions to the sociological study of sport. In J. Maguire \& K. Yung (Eds.), Theory, Sport \& Society. London: Jai.

Elias, N. \& Dunning, E. (1986). Quest for Excitement: Sport and Leisure in the Civilizing Process. Oxford: Basil Blackwell. 
Guttmann, A. (2004) From Ritual to Record: The Nature of Modern Sport (revised ed.). New York: Columbia University Press.

Kosiewicz, J. (2010a). Sport and Philosophy: From Methodology to Ethics. Warsaw: Wydawnictwo BK.

Kosiewicz, J. (2010b). Social and Biological Context of Physical Culture and Sport. Physical Culture and Sport. Studies and Research, 50, 5-32. DOI: 10.2478/v10141-010-0021-1

Kosiewicz, J. (2012). Considerations on General Assumptions on the Sciences of Sport. Physical Culture and Sport. Studies and Research, 56, 65-101. DOI: 10.2478/pcssr-10141-010-0021-1

Kosiewicz, J. (2014a). The Normative Ethics and Sport: A Moral Manifesto. Physical Culture and Sport. Studies and Research, 62(1), 5-22. DOI: 10.2478/pcssr-2014-0008

Kosiewicz, J. (2014b). Sport beyond Moral Good and Evil. Physical Culture and Sport. Studies and Research, 62(1), 23-31. DOI: $10.2478 /$ pcssr-2014-0009

Kosiewicz, J. (2014c). Foul Play in Sport as a Phenomenon Inconsistent with the Rules, yet Acceptable and Desirable. Ethical Conditions. Physical Culture and Sport. Studies and Research, 62(1), 32-47. DOI: 10.2478/pcssr-2014-0010

Kosiewicz, J. (2014d). The Ethical and Legal Context of Justifying Anti-Doping Attitudes. Physical Culture and Sport. Studies and Research, 62(1), 48-63. DOI: 10.2478/pcssr-2014-0011

Kosiewicz, J. (2014e). Sport and Social Deviations - APrognostic Attitude. Physical Culture and Sport. Studies and Research, 62 (1), 64-73. DOI: 10.2478/pcssr-2014-0012

Kosiewicz, J. (2014f). Sport and Art: Differences and Theatrical Similarities. Physical Culture and Sport. Studies and Research, 63, 60-78. DOI: 10.2478/pcssr-2014-0022

Kosiewicz, J. (2015a). Why Pluralism, Relativism, and Panthareism: An Ethical Landscape with Sport in the Background. Physical Culture and Sport. Studies and Research, 66, 75-87, DOI: 10.1515/pcssr-2015-0015

Kosiewicz, J. (2015b). Sport i sztuka - różnice i zbliżenia /Sport and Art: Differences and Theatrical Similarities/. In M. Zowisło \& J. Kosiewicz (Ed.), Sport i turystyka w zwierciadle wartości społecznych /Sport and Tourism in the Mirror of Social Values/ (pp. 11-36). Kraków: Wydawnictwo Akademia Wychowania Fizycznego w Krakowie.

Kosiewicz, J. (2016a). Considerations on Relation between Philosophy of Sport and Common Sense Thinking. Physical Culture and Sport. Studies and Research, 70, 79-87. DOI: 10.1515/pcssr-2016-0010

Kosiewicz, J. (2016b). Moralność i sport /Morality and Sport/. Warszawa: Międzynarodowe Towarzystwo Nauk Społecznych o Sporcie /International Society for the Social Sciences of Sport/.

Kretchmar, R.S. (2008). Games Came from "Nowhere" and "Somewhere"... At the Same Time. Studia Humanistyczne /Humanistic Studies/, 8, 43-49.

Kretchmar, R.S. (2009). Do Games Require Artificial Problems that Are Neither Too Hard Nor Too Easy? Typescript of International Association for the Philosophy of Sport Conference Presentation, August 2009, Seattle, Washington.

Matusewicz, C. (1995). Widowisko sportowe /Sporting Spectacle/. In Z. Krawczyk (Ed.), Kultura fizyczna $i$ sport /Physical Culture and Sport/. Encyklopedia Kultury polskiej, vol III. Warszawa: PWN.

McPherson, B.D., Curtis, J.E. \& Loy, J.W. (1989). Defining sport. In B.D. McPherson., J.E. Curtis \& J.W. Loy (Eds.), The Social Significance of Sport. Champaign, IL: Human Kinetics.

Meier, K.V. (1995). Triad Trickery: Playing with Sport and Games. In W.J. Morgan \& K.V. Meier (Eds.), Philosophic Inquiry in Sport. Champaign, IL: Human Kinetics.

Raszewski, Z. (1976). Partytura teatralna/Theatrical score/. In Wprowadzenie do nauki o teatrze/ Introduction to the Study of Theatre/, t. I. Wrocław: Ossolineum.

Raszewski, Z. (1991). Teatr w świecie widowisk: Dziewięćdziesiqt jeden listów o naturze teatru /Theatre in the World of Stage Performances: Ninety-One Letters About the Nature of Theatre/. Warszawa: PWN.

Schaffer, B. (1975). Mały informator muzyki XX wieku /A Small Companion to the $20^{\text {th }}$ Century Music/. Kraków: PWM.

Schaffer, B. (1979). Historia muzyki: style i twórcy/The History of Music: Styles and Composers/. Poznań: Młodzieżowy Ruch Miłośników Muzyki Pro Sinfonika.

Schaffer, B. (1985). Dzieje muzyki /The History of Music/. Warszawa: WSiP. 
Suits, B. (1995a). The Elements of Sports. In W.J. Morgan \& K.V.Meier (Eds.), Philosophic Inquiry in Sport. Champaign, IL: Human Kinetics.

Suits, B. (1995b). Tricky Triad: Play, Game and Sport. In W.J. Morgan \& K.V. Meier (Eds.), Philosophic Inquiry in Sport. Champaign, IL: Human Kinetics.

Suits, B. (2016). Konik polny: gry, życie $i$ utopia /The Grasshopper: Games, Life and Utopia/. Warszawa: Wydawnictwo Aletheia.

Tomc, G. (2008). The Nature of Sport. In M. Doupona Topič \& S. Ličen (Eds.), Sport, Culture \& Society. Ljubljana: University of Ljubljana.

AUTHOR'S ADDRESS: $\quad$ Jerzy Kosiewicz Josef Pilsudski University of Physical Education in Warsaw Department of Philosophy and Sociology

00-968 Warsaw

34 Marymoncka str.

Poland

E-mail: jerzy.kosiewicz@awf.edu.pl

Received: 20 November 2016; Accepted: 25 January 2017 